\title{
Endocrine disruption by PFAS: a major concern associated with legacy and replacement substances
}

\author{
Emiliano Panieri $^{1^{*}}$, Aleksandra Buha Đorđevic ${ }^{2}$, Luciano Saso ${ }^{1}$ \\ ${ }^{1}$ Department of Physiology and Pharmacology "Vittorio Erspamer", Sapienza \\ University of Rome, 00185 Rome, Italy \\ ${ }^{2}$ University of Belgrade - Faculty of Pharmacy, Department of Toxicology "Akademik \\ Danilo Soldatović", Belgrade, Serbia
}

* Corresponding author: Emiliano Panieri, e-mail: emiliano.panieri@isprambiente.it

\begin{abstract}
Per- and poly-fluorinated alkyl substances (PFAS) have been used for decades in a great variety of processes and products by virtue of their exceptional properties, versatility and chemical stability. Nevertheless, it is increasingly recognized that these substances can represent a serious hazard to human health and living organisms due to their persistence, long-range transport potential and tendency to accumulate in biota. For this reason, some efforts have been made across the EU to identify alternative molecules, with a shorter carbon chain and theoretically safer profile, that might replace the previous generation of legacy PFAS. Unfortunately, this strategy has not been entirely successful and serious concerns are still posed by PFAS in different human populations. Among others, an emerging aspect is represented by the adverse effects that both legacy and alternative PFAS can exert on the human endocrine system, with respect to vulnerable target subpopulations. In this review we will briefly summarize PFAS properties, uses and environmental fate, focusing on their effects on human reproductive capacity and fertility, body weight control and obesity as well as thyroid function.
\end{abstract}

Keywords: PFAS; human health; endocrine disruption; environment

doi.org/10.5937/arhfarm71-34197 


\section{Introduction}

Per- and poly-fluorinated alkyl substances (PFAS) are a wide and heterogeneous family of synthetic chemicals that have recently gained increasing attention due to their potential impact on human health and wildlife (1-3). By virtue of their unique chemical structure, conferring exceptional thermal and chemical stability in addition to water repellence and tensioactive properties, PFAS have been used in a variety of industrial processes and consumer products including firefighting foams, textiles, anti-adherent coatings, food packaging, cosmetics and paints (4). Once released into the environment, these substances are recalcitrant to degradation processes, can migrate towards distant sites and tend to bioaccumulate into living organisms, ultimately entering into the food webs of different ecosystems $(5,6)$. While many efforts have been made to define the toxicological effects of PFAS on susceptible human subpopulations, our knowledge is still limited to few individual substances such as perfluorooctane sulfonic acid (PFOS) and perfluorooctanoic acid (PFOA), which, despite having been phased out by the major producers, are still largely present in the environmental media across the globe $(1,7)$. Unfortunately, there is still a tremendous gap of toxicological information related to the vast majority of other PFAS, consisting of around 4700 different substances, including those introduced as replacement alternatives due to their supposedly safer profile $(8,9)$. Increasing concerns for human populations exposed to significant levels of PFAS are related to the short-term and long-term effects, which can potentially lead to an increased mortality rate, promote carcinogenesis, alter the pattern of DNA methylation or induce dysfunction at the level of lipid metabolism, neurodevelopment, immune and endocrine systems (10-15). In this respect, there is a growing interest in assessing chemicals that can interfere with hormonal function - a specific class of substances known as endocrine disruptors (EDs) - and their impact on human health (16). Accumulating evidence suggests that PFAS can also act as endocrine disrupting molecules, exerting proestrogenic (17) or anti-androgenic effects (18), as well as antagonistic activities at the level of thyroid hormone signalling both in vitro an in vivo $(18,19)$, thus raising additional concerns, especially for the most vulnerable categories such as pregnant women, children, newborns and the elderly (20-24). In light of this problematic aspect, in this review we aim to summarize the current knowledge on PFAS as endocrinedisrupting agents in humans, focusing on legacy substances as well as short-chain substitutes.

\section{PART I: PFAS chemical properties, use, emissions and environmental fate}

\section{PFAS chemistry, properties and uses}

The broad category of PFAS substances comprises more than 4700 compounds, constituted by a hydrophobic carbon chain of variable length (ranging from $\mathrm{C} 4-\mathrm{C} 17$ ), wherein carbon-fluoride and carbon-hydrogen bonds alternate to form one or more perfluoroalkyl moieties $\left(-\mathrm{C}_{n} \mathrm{~F}_{2 n+1-}\right)$ and a terminal group that confers hydrophilic 
properties (25). The functional groups, which are located in the terminal head region of the molecule, typically include sulfonates, sulfates, phosphates, carboxylates, amines, as well as alcohols or their combination, identifying subgroups of PFAS that can exist in a neutral, ionic or zwitterionic form, depending on the specific environmental conditions $(26,27)$. As for the tail structure, the main carbon-fluoride chain can be linear or branched, with a partial or total degree of fluorination. The former case is related to polyfluorinated compounds, while the latter case identifies the perfluorinated compounds, a subgroup that entails some of the most well-studied PFAS, such as perfluorooctane sulfonate (PFOS) and perfluorooctanoic acid (PFOA) $(25,28,29)$. The numerous possible combinations of these chemical features generate an extraordinary variability. The variability is largely responsible for the unique properties of these compounds and their wide applicability in numerous industrial processes and products. The carbon-fluoride bond is the shortest and the strongest known in organic chemistry. This bond confers very high resistance over a wide range of thermal, chemical and environmental conditions and its amphipathic nature imparts additional properties as surfactants. The chemical properties of PFAS are also responsible for their resistance to biotic or abiotic degradation and long-range transport potential across different environmental media, leading to environmental persistence, increased entrance into the food chain and the bioaccumulation into living organisms $(5,30-32)$. From a historical perspective, PFAS have been manufactured since the late 1940s, but the first studies assessing their effects on exposed human beings $(33,34)$ and their occurrence in the environmental media worldwide (35-37) lagged behind for many years. Since their introduction, PFAS have largely been employed as coating treatment with water, oil and grease-repellent properties for food paper containers and anti-adherent cooking pots, as surface treatment of leathers, photographic films and textiles (i.e. stain-resistant upholstery or carpets) or in the manufacture of firefighting foams, biocides, paints, semiconductors, cosmetics, packaging material, furniture, medical and cleaning products (38).

\section{PFAS environmental releases, distribution and fate}

By virtue of their unique properties and widespread uses, PFAS substances have become ubiquitous and are detected in almost every part of the globe, raising major concerns about their impact on human health and ecosystems $(39,40)$. In this respect, multiple sources of PFAS emissions have been identified throughout their whole lifecycle. Major sources are represented by direct wastewater releases, air emissions and disposal of PFAS-contaminated material into soil from industrial manufacture processes or the intentional use of firefighting foams that contain PFAS in their formulation (41, 42). Relevant secondary sources can be ascribed to the formation of biosolids from the industrial and municipal wastewater treatment plants and their subsequent disposal or direct application to the agricultural lands $(43,44)$. Aside from the primary sources of PFAS contamination, additional sources derive from the use and disposal of PFAScontaining products. Disposal by consumers is considered a minor source of environmental release $(40,45,46)$. Once released into the environment, PFAS substances 
are subject to many different mechanisms that regulate their fate and transport across different compartments and ultimately determine the targeting of the final receptors, either humans or wildlife. The redistribution of PFAS compounds in the environment (air, soil, water) is dependent on the complex interaction between chemical properties and the specific conditions existing within the environmental media (47-50). Partitioning processes such as electrostatic or hydrophobic interactions drive PFAS adsorption to and desorption from the organic matter in the soil and water sediments while the volatilization and the interaction with the small particulate matter influences their diffusion into air (5154). Redistribution of PFAS substances within and between the different environmental media occurs through a combination of transport processes that include atmospheric dispersion through the wind or the airborne particles and subsequent deposition through wet or dry mechanisms, but also soil run-off and leaching to surface or groundwater due to precipitation, flooding, or irrigation events (55-59). Lastly, biotic or abiotic transformation processes can promote PFAS speciation and their conversion into other compounds $(60,61)$, as occurs, for example, in the case of several fluorochemicals (e.g. 6:2 FtS, 8:2 FTOH, FOSE and FOSA) that can act as precursors of the most common PFAS substances such as PFOS and PFOA (62-65).

\section{PART II: Legacy pfas and their alternatives as endocrine-disrupting agents}

PFOA and PFOS, regarded as the most representative members of legacy PFAS affecting both humans and the environment, have been the focus of extensive research over the last years. The growing concerns over PFAS effects have led major producers and importers to voluntarily phase out these substances (66), prompting other companies to follow. This concern later led to the US-EPA PFOA stewardship program that was committed to the removal of PFOA from emissions and products by 2015 (67). Recently, policy makers and regulators under the UN's Stockholm Convention on persistent organic pollutants (POPs) have implemented two restrictive legislative measures targeting PFOS and PFOA. The first, in 2019, aimed to restrict the manufacturing, marketing and use of PFOS in the EU. The second, enacted in 2020, aimed to completely ban the production and use of PFOA or its derivatives in more than 160 countries (68-71). In response to these measures, several manufacturers have started to introduce alternative PFAS with shorter carbon chains and supposedly safer toxic profiles. Unfortunately, despite the limited number of available data, some evidence suggests that even these novel substitutes can potentially pose serious concerns for the ecosystem and humans, which is the reason why some of these PFAS are currently under regulatory scrutiny in the REACH Regulation.

In the following paragraphs, we will describe the major routes through which PFAS can enter into contact with human receptors, and we will summarize the evidence supporting the endocrine-disrupting effects by legacy PFAS and their alternatives, when available. 


\section{PFAS exposure pathways relevant for humans and their effects on human health}

In terms of human exposure, both direct and indirect mechanisms can play a significant role through multiple pathways that can also operate concomitantly (72). Inhalation of PFAS-contaminated air during the manufacturing processes, or dermal contact with PFAS-containing material are critical occupational modes of exposure. The general population is mainly subjected to indirect exposure via the environment or the ingestion of contaminated food and water $(39,57,73-75)$. Once in the human body, PFAS are not efficiently eliminated due to a half-life that sometimes lasts for several years (76) and tend to bioaccumulate into the blood, the liver, the placenta and other organs, owing to their high affinity for serum proteins or protein receptors (e.g. albumin, transthyretin, fatty acids binding protein, human pregnane $\mathrm{X}$ receptor) (77-81). Several adverse effects have already been documented in different human populations, including hepatotoxicity, immunotoxicity, neurotoxicity and renal toxicity, but also increased mortality, augmented cancer incidence, alterations of the lipid metabolism and the endocrine systems, the latter being an emerging concern worldwide and the focus of the next paragraphs.

\section{PFAS impacts on the endocrine system and biological mechanisms}

It is increasingly recognized that endocrine disruptors (EDs) are chemicals of great concern for human health and growing interest has emerged around these substances in the last decade, when they started to enter into the international chemical policy arena (82). Since then, many efforts have been made to rapidly gain scientific knowledge on the impact of EDs on human health (83-86) and the environment (87-90). The growing number of these substances (greater than 1000) that involves well-known chemicals such as Phthalates, Polychlorinated biphenyls, DDT and Bisphenol A, has recently been expanded with the inclusion of PFAS, due to their documented interference with hormone function in humans and wildlife (91-94). A serious concern is that, with the expansive number of PFAS-containing compounds present on the market, the number of studies directly assessing their toxic effects is quite limited. For this reason, alternative approaches based on QSAR (Quantitative Structure-Activity Relationship) in silico modelling have been explored to tentatively fill this huge gap of information and the same time reduce the use of animal testing $(78,95,96)$. Other methods, based on a screening of the existing literature, have also been proposed. In this regard, a systematic evidence map has been recently utilized by Pelch et al. to summarize the available scientific evidence from in vitro, in vivo, as well as epidemiological studies related to 29 individual PFAS substances of concern for health effects on humans and biota (97), which is publicly available (98). Apart from legacy PFAS, such as PFOS and PFOA, whose endocrine disruptive effects are well recognized, the data suggest that short-chain alternatives such as PFBS, PFHxS, PFTrDA and GenX can affect hormone activities and physiology in non-occupationally exposed humans and other living organisms (99-102). Another longitudinal study on a Danish birth cohort, investigating potential effects of different PFAS on pubertal development, reported that prenatal exposure to PFOS, 
PFNA, PFDA, PFHxS and PFHpS, was associated with an earlier onset of typical puberty indicators in girls, an effect that was also present in boys, although limited to PFHxS and PFHpS. By contrast, male individuals exposed to PFNA and PFDA exhibited a later appearance of pubertal markers, suggesting sex-specific and PFAS-specific effects (103). A cross-sectional study from Di Nisio et al. examined the association between PFAS exposure and bone status in a cohort of young male residents of a heavily contaminated area. The authors observed a significant reduction of bone density in the exposed subjects and an enhanced risk of bone fracture, which appeared to depend on direct binding to and interference with hydroxyapatite, the main component of bone matrix, as evidenced by docking modelling simulation on PFOA (104). More recently, Braun et al. analyzed the serum concentrations of PFOA, PFOS, PFHxS and PFNA in a cohort of children with high gestational and childhood exposure to identify potential correlations with cardiometabolic risks. The outcome of their study revealed that gestational and cord PFOA, PFHxS concentrations were positively associated with cardiometabolic risk scores during adolescence, most likely by inducing alterations in the insulin and HOMA-IR levels, as well as increased leptin levels, but lower adiponectin to leptin ratio, in the absence of sex-specific trends (105). Although additional epidemiological evidence is required to further substantiate these observations, the available studies indicate that specific subpopulations or life stages can exhibit a marked susceptibility to PFASendocrine disruptive effects.

\section{PART III: Effects of pfas exposure on the human endocrine systems}

\section{PFAS effects on human reproductive function and fertility}

Accumulating evidence indicates that PFAS might negatively impact the reproductive function and fertility of males and women $(114,115)$. The disruptive function of PFAS can act at multiple levels. For example, it has been shown that chronic exposure of male rats to PFDoA $(0.5 \mathrm{mg} / \mathrm{Kg} / \mathrm{bw})$ could significantly reduce the serum testosterone levels and alter the morphology of seminiferous tubules. Mechanistically, the diminished testosterone content was caused by molecular alterations in steroidogenesis. Reductions in testosterone were due to decreased mRNA/protein of a key steroidogenesis regulator, stAR (Steroidogenic Acute Regulator), and the abrogated gene expression for the hypothalamic androgen receptor (AR), pituitary follicle-stimulating hormone (FSH) and pituitary gonadotropin-releasing hormone receptor $(\mathrm{GnRH}-\mathrm{R})(116)$. Deregulation of the hypothalamic-pituitary-testis (HPT) axis was also reported in male rats treated with PFOS in the long term, leading to altered GnRH, LH, FSH expression and testosterone secretion that was paralleled by histological alterations at the level of testis, hypothalamus and the pituitary gland (117). These observations were substantiated and further extended by a subsequent study from the same group, indicating that the effects of PFOS were even broader and also affected the expression and content of the respective receptors, GnRHR, LH-R, FSH-R, in some cases producing opposite effects at the transcriptional and protein level within a specific gland (118). Similarly, transactivation and steroidogenesis assays conducted on H295R cells showed that PFOS and PFOA could impair testosterone 
synthesis by altering the expression of steroidogenic genes and exerting both proestrogenic and anti-estrogenic activities (119). Moreover, both these PFAS were found to inhibit steroidogenic in vitro secretion in porcine theca and granulosa cells subjected to stimulation with gonadotropins (120). In humans, PFOS serum levels have been inversely associated with sperm morphology in Arctic and European populations (121) and the exposure to environmentally relevant concentrations to Me-PFOSA-AcOH, PFDeA, PFNA, PFOA, PFOS, PFOSA has been associated with diminished semen quality in male individuals residing in two US regions (122). By analysing 178 healthy and naturalcycling women, Barrett et al. found that PFOS and, to a lesser extent, PFOA serum concentrations, were negatively associated with E2 and progesterone levels, suggesting that these substances might impair women's fertility by suppressing ovarian hormone levels (123). Similarly, Tsai et al. focused on young adolescents and young adults to reveal that serum levels of PFAS, in particular PFOA, PFOS and PFUA, were inversely associated with the serum levels of the reproductive hormones testosterone, FSH, and SHBG (sex-hormone binding globulin) (124). Epidemiological evidence also suggests that PFAS can prolong the time required to become pregnant (TTP) in exposed females. In this respect, some studies found that higher blood levels of PFOA, PFOS, PFHxS and PFNA were associated with longer TTP or infertility (125-128) while others indicate that increased blood levels of PFOA predispose to an increased risk of sporadic miscarriage in early pregnancy and during the second half of the first trimester, a common complication of pregnancy (129).

In other cases, PFAS have been shown to promote endometriosis, which is one major cause of female infertility. This has been evidenced by a study from Wang et al. wherein blood concentrations of ten different PFAS were measured in 173 Chinese women suffering from infertility and with surgically confirmed diagnosis of endometriosis (130). The authors observed a significant association between plasma levels of PFBS, a substitute of PFOA and the risk of endometriosis-related infertility, also revealing wide exposure to this substance. Later work conducted in another cohort of Chinese women exposed to high levels of PFAS also revealed that the blood concentrations of PFOA, PFOS and PFHxS, were positively associated with an increased risk of primary ovarian insufficiency (131). Intuitively, women residing in heavily contaminated regions are particularly prone to multiple dysfunctions, as evidenced by a recent study from Di Nisio et al. conducted on young women (aged 18-21) residing in the Veneto region (132). The authors observed that the age at menarche and the risk of irregular menstruation periods were significantly higher in the group exposed to PFOA than in the relative controls, also providing in vitro evidence from Ishikawa cells experiments suggestive of altered progesterone activity and endometrial dysfunctions. Notably, previous observations from the same group consistently reported that young males residing in the Veneto Region displayed multiple hallmarks of infertility. Indeed, increased levels of PFOS/PFOA in plasma and seminal fluid were found to positively correlate with a decreased semen quality, mean testicular volume, shorter penile length and increased signs of feminization (lower anogenital distance) (115). It has also been 
hypothesized that PFAS exposure can represent an important cause of maternal morbidity and mortality, since positive associations have been reported between PFOA, PFOS, PFBS, PFNA, PFHxS, PFHpA, and the risk for hypertension disorders of pregnancy (133), but further investigations in larger cohorts will be necessary.

Additionally, PFAS can affect human reproductive capacity through the alteration of foetal development, which has been shown in animal models (134-136). In humans, several reports indicate that perinatal exposure to PFOS, PFOA, PFNA, PFHxS or PFDA is inversely associated with placental function, foetal growth and infant birth weight (137141). Other evidence suggests that placental transfer of PFAS $(79,142)$ can interfere with normal lung development (143) and gross-motor control (144), predisposing to neuropsychological, cognitive and behaviour disorders (145-149). A list of the effects of PFAS exposure on human reproductive function and fertility is shown in Table 1.

Taken together, the available experimental and epidemiological evidence suggests that both legacy and alternative PFAS can affect the fertility of male and female individuals at multiple levels. Currently, most of our knowledge is limited to longitudinal and observational studies, requiring additional work to better elucidate the cellular and molecular mechanisms underlying these alterations.

\section{PFAS effects on human body weight and obesity}

The data from the last decade indicate that PFAS exposure during the prenatal period, childhood or adult life is correlated with obesity and overweight. Similarly to other endocrine disruptors, PFAS can influence body weight by altering the homeostatic balance between appetite and satiety or by inducing disturbances in the lipid metabolism that might promote adipogenesis and lipid accumulation. An early study from Hines et al. has shown that exposure of female mice to low doses of PFOA $(0.01-0.3 \mathrm{mg} / \mathrm{kg})$ significantly increased body weight and the serum levels of both insulin and leptin in midlife mice after development and up to adulthood. Interestingly, these effects were not observed in the case of prenatal exposure to higher doses of PFOA or adults exposure, thus suggesting that the obesogenic effects of PFOA might occur under specific exposure concentrations and life stages (150). Additional studies on animal models indicate that PFAS can deregulate lipid metabolism, most likely through the impairment of lowdensity lipoproteins excretion $(151,152)$, induce alterations in the composition of polyunsaturated fatty acids (PUFAs) (153) or even exert pro-adipogenic effects by promoting lipid accumulation and the terminal differentiation of preadipocytes from murine and human origin into adipocytes $(154,155)$.

In parallel with these studies, several epidemiological investigations have been conducted in humans, some cases with conflicting results, since a decrease in circulating PFAS levels might derive from changes in serum protein concentrations, reduced food intake, adsorption and metabolism (156-160). Since this dichotomy still needs to be fully elucidated, we will mainly focus on some representative studies wherein PFAS exposure has been positively correlated with anthropometric signs of obesity in humans. For instance, a prospective study on Danish pregnant women revealed that prenatal exposure 
to low doses of PFOA, but not to other PFAS, was positively associated with an increased body-mass index (BMI) and waist circumference in 20-year-old females, but not male individuals (161). Consistently, the so-called HOME study, examining the relationship between prenatal exposure to PFAS in pregnant women from the US and the effects on the offspring's adiposity, showed that higher serum PFOA concentrations during pregnancy were associated with higher BMI, waist circumference and body fat content in 8-year-old children, but also with more rapid BMI increases in children aged 2-8 (162). In agreement with these findings, a positive (yet mild) association between maternal PFOS, PFOA, PFNA, PFHxS and mid-childhood overweight in females with a median age of 7.7 years was observed by Mora et al. (163), while a positive association was found by Karlsen et al. between maternal serum levels of PFOS and PFOA and BMI and/or overweight risk in preschool children (164). Evidence also indicates that the effects of PFAS are not limited to prenatal exposure, but can instead also affect exposed adolescents and adults. Accordingly, in a large cohort comprising 1612 Chinese adults, Tian et al. assessed the obesogenic effects of different PFAS, including five novel structural isomers of PFOA and PFOS. The authors observed that the exposure to these substances, especially PFOA and its isomers, was significantly associated with an increased BMI and waist circumference, two good indicators of an obesogenic effect, which was more pronounced in the females (165). Another cross-sectional study analysing an even larger cohort of 2473 US children, aged 12-18 years, found a positive correlation between the plasmatic levels of PFOA and the increased BMI or waist circumference, indicating that adolescence is also a time window of vulnerability to PFAS exposure (166). This has been further substantiated by a recent study from Averina et al. conducted on 940 Norwegian adolescents with a mean age of 16.4 years (167). Here, the authors found a positive association between the exposure to PFOS, PFNA, PFDA and PFUnDA with apolipoprotein B, total cholesterol and LDL-cholesterol, while PFHxS and PFHpS levels were positively associated with the risk of obesity. Notably, the sum of PFAS concentrations and the levels of individual substances, namely PFOS, PFDA, PFNA and PFUnDA, were positively associated with the risk of dyslipidemia while $\sum$ PFAS, PFOS, PFOA and PFHxS, were positively associated with the risk of hypertension, thus suggesting that exposure to PFAS during adolescence might predispose to cardiovascular disease in adult life. A list of the effects of PFAS exposure on human body weight and obesity is shown in Table 2.

In conclusion, both experimental and epidemiological data support the notion that PFAS can induce disturbances in the control of body weight and lipid metabolism. This seems particularly evident when the exposure to PFAS substances occurs during life stages of susceptibility, such as gestational life, childhood or adolescence. It has to be recognized, however, that several studies have failed to reveal positive correlations between PFAS and anthropometry. These discrepancies might be explained by the concomitant presence of intrinsic limitations, including the small size of the investigated population, or the presence of confounding variables such as lifestyle factors, age, sex, 
which need to be adjusted to increase the statistical power and limit the impact of potential bias.

\section{PFAS effects on thyroid hormone signalling}

One of the best-documented effects of PFAS substances on the endocrine system is the disruption of thyroid functions. This is of particular relevance for human health, since thyroid hormones affect virtually every single organ of human body across different life stages (from intrauterine to adult life) $(168,169)$. For this reason, disturbances in thyroid signalling can potentially cause profound alterations of multiple systems and organs and amplify the adverse effects of PFAS substances.

Similarly to other endocrine-disrupting chemicals, PFAS can affect thyroid function by altering thyroid hormones biosynthesis, metabolism and secretion (168). This process requires a series of coordinated events, including iodide uptake from sodium/iodide symporter (NIS), thyroglobulin synthesis and iodination by the enzyme thyroid peroxidase (TPO). Evidence from in vitro and in vivo studies indicates that this can occur through many different mechanisms. For example, it has been shown that subchronic exposure of rats to PFOS could decrease serum T4 levels without affecting TSH levels, by enhancing its hepatic glucuronidation via Uridine diphosphoglucuronosyl transferase 1A1 (UGT1A1) and its thyroidal conversion to T3 via type 1 Deiodinase (DIO1) (19).

Moreover, PFOS, PFOS-K and PFHS-K were ranked as highly inhibitory substances of the human sodium/iodide symporter (NIS) in a high-throughput screening and chemotype-enrichment analysis conducted by Wang et al. (170). Similarly, PFOA was found to significantly suppress the NIS-dependent iodide uptake in FRTL-5 thyrocytes (171). Other evidence suggests that PFOS and PFOA can disrupt thyroperoxidase (TPO) activity in FTC-238 cells (172). Additional mechanisms are represented by competitive binding to the T3-T4 binding proteins transthyretin and thyroxine-binding globulin, which might interfere with the transport of thyroid hormones respectively in rats and humans (113), or by altering the expression of genes involved in thyroid hormones homeostasis, such as corticotropin releasing hormone b (crhb), iodothyronine deiodinase 3a (dio3a), thyroid-stimulating hormone receptor (tshr) and nkx2 homeobox1 (nkx 2.1) in zebrafish embryos (14). Moreover, since PFAS can promote an increased production of autoantibodies against thyroglobulin in some specific cases, it is also conceivable that the TGAb might indirectly affect the synthesis of thyroid hormones in the exposed individuals by decreasing the levels of circulating TG, although this hypothesis still needs to be conclusively proven (173).

As already mentioned, various epidemiological studies have been conducted to evaluate the effects of maternal PFAS exposure in newborns, as well as potential alterations related to postnatal or adult exposure of the general population. As it is known, pregnancy is a critical time wherein even slight alterations of thyroid hormones can have a significant impact on the foetal development, especially in presence of other concomitant stressors. For example, it has been reported that legacy and alternative PFAS 
could induce differential changes in the thyroid hormones of pregnant women with biomarkers of autoimmune thyroiditis (high TPOAb levels), compared to women with a healthy thyroid gland. Indeed, PFHxS, PFNA, PFOA and PFOS serum concentrations were weakly associated with a decrease in free T4 levels. By contrast, PFNA, PFOA and PFOS were strongly and positively associated with TSH in the former but not in the latter groups. The authors speculated that, despite the small sample size, even low PFAS exposure might exacerbate pre-existing conditions typically encountered during early pregnancy (i.e. low free T4 and high TSH levels) in women with high TPOAb, thus potentially affecting the neurodevelopment of the newborns (174). In line with these data, Guo et al. assessed the potential effects on thyroid hormones of newborns upon prenatal exposure to legacy or alternative PFAS, both as individual substances and as mixtures (175). It was found that the cord serum levels of PFAS mixtures were positively associated with lower TSH but higher total and free T4 concentrations in the newborns, with PFNA and PFHpA exerting the larger contribution to the former while PFOS and PFNA played a major role in the latter effects. Other work from Preston et al. further extended these observations, providing evidence that prenatal PFAS exposure can affect thyroid function in both mothers and infants. 2128 mother-child pairs were analysed, among which 1645 had maternal plasmatic PFAS measurements from early phases of pregnancy. The results showed that higher levels of PFOA, Me-FOSAA, and PFHxS were associated with lower levels of free T4 during early pregnancy compared to women with the lowest levels. In the subset of TPOAb-positive women, increases in PFOA, PFOS, and PFNA were associated with lower TSH levels. In addition, newborns having higher prenatal concentrations of PFHxS, PFOS, PFOA also exhibited lower concentrations of T4, an alteration that occurred specifically in male, but not female, infants (176). Later work from Preston et al. assessed the concentrations of PFOA, PFOS, PFNA, PFHxS, EtFOSAA and Me-FOSAA in a cohort of 726 pregnant women and 465 neonates (177). By assessing joint and individual effects of PFAS exposure, the authors found that higher levels of the PFAS mixture were associated with lower levels of free T4 in the mothers, (with PFOA, PFHxS, Me-FOSAA and Et-FOSAA, contributing most) while an inverse association was seen between the levels of the PFAS mixture and the T4 concentration in male neonates.

Work by Caron-Beaudoin et al. focused on children and youths belonging to two distinct First Nation communities in Quebec (178). From the measurement of PFOS, PFOA, PFHxS and PFNA serum levels, the latter was present at very high levels and a positive association was found with free T4 concentrations, mainly among male individuals. These results, in agreement with the previous findings, suggest that PFAS exposure in children can induce alterations in T4 without affecting other regulators of thyroid function, such as TSH or TG $(179,180)$.

Interestingly, a longitudinal study from Blake et al. investigated potential health effects induced by the exposure to eight different PFAS in a cohort of adults (mean age 38 years) enrolled in an 18-year biomonitoring (181). It was reported that the serum levels of PFOS were positively associated with the concentrations of TSH and inversely 
associated with the levels of T4, an effect that was more pronounced in males. Instead, females exhibited a significant association between the first serum measurement of PFNA and the levels of total T4, suggesting sex-specific effects of individual PFAS substances also in the general adult population. A list of the effects of PFAS exposure on human thyroid function is shown in Table 3.

In summary, accumulating evidence indicates that long-chain and shorter-chain PFAS substances can deregulate thyroid functions in multiple ways, affecting the general population and communities subjected to environmentally relevant exposure. While, in general, specific categories such as pregnant women, infants and children might be particularly prone to PFAS-induced thyroid dysfunction, evidence exists on adverse effects in adult males and females. It is envisaged that novel and larger studies will be designed to assess the contribution of PFAS as individual substances and as mixtures to elucidate which specific compound or their combination can induce sex-specific or even life stage-specific effects. It is also important to investigate if the associated forms of subclinical hypothyroidism will later evolve into an evident pathologic condition.

\section{Conclusions and future perspectives}

In the last decade we have witnessed an increasing interest in defining the impact of PFAS substances on human health and the ecosystems. While the so-called legacy PFAS (e.g. PFOA, PFOS) have been phased out in many countries or have been subjected to legislative regulatory measures that limit their uses, their persistence and wide distribution across the globe have nevertheless produced a number of adverse effects in the exposed population. Among them, the endocrine disruptive activity represents one of the most serious concerns. Accumulating evidence from both in vitro, in vivo and epidemiological studies suggest that PFAS can induce disturbances in the estrogens or testosterone signalling, in the hormones controlling human fertility or the homeostatic control of satiety/appetite or affect thyroid functions. Notably, their interaction with multiple endocrine systems that control crucial aspects of human biology implies that PFAS compounds can exert their adverse effects in different subpopulations and life stages, with important implications for those categories such as pregnant women, infants and children that are particularly vulnerable to their exposure. In this regard, even PFAS substitutes that have been introduced to replace legacy PFAS with less toxic alternatives, appear not to possess a safer profile in terms of endocrine disruptive effects, suggesting that a global regulatory action might be necessary to target the whole PFAS category, rather than individual substances. Meanwhile, additional studies are required to shed light on the long-term effects of PFAS exposure in the general population and to elucidate the mechanisms through which single PFAS or their combination in a mixture can affect the endocrine system. From this perspective, larger cohorts stratified for sex, age and lifestyle habits appear to be a prerequisite for the design of epidemiological studies with the appropriate statistical power and devoid of confounding variables that might preclude the identification of potential associations between PFAS and hormone functions/anthropometry. Furthermore, promising results are expected to derive from the 
implementation of human health risk approaches integrating data form cell cultures, animal models and physiologically based pharmacokinetic modelling. In conclusion, there is no doubt that the assessment of PFAS exposure and its impact in human health, with particular emphasis on the endocrine system, will be one of the major challenges in the future.

\section{References}

1. De Silva AO, Armitage JM, Bruton TA, Dassuncao C, Heiger-Bernays W, Hu XC, et al. PFAS Exposure Pathways for Humans and Wildlife: A Synthesis of Current Knowledge and Key Gaps in Understanding. Environ Toxicol Chem. 2021;40:631-57.

2. Ankley GT, Cureton P, Hoke RA, Houde M, Kumar A, Kurias J, et al. Assessing the Ecological Risks of Per- and Polyfluoroalkyl Substances: Current State-of-the Science and a Proposed Path Forward. Environ Toxicol Chem. 2021;40:564-605.

3. Lindstrom AB, Strynar MJ, Libelo EL. Polyfluorinated compounds: past, present, and future. Environ Sci Technol. 2011;45:7954-61.

4. Gluge J, Scheringer M, Cousins IT, DeWitt JC, Goldenman G, Herzke D, et al. An overview of the uses of per- and polyfluoroalkyl substances (PFAS). Environ Sci Process Impacts. 2020;22:2345-73.

5. Wang $\mathrm{W}$, Rhodes G, Ge J, Yu X, Li H. Uptake and accumulation of per- and polyfluoroalkyl substances in plants. Chemosphere. 2020;261:127584.

6. Koch A, Jonsson M, Yeung LWY, Karrman A, Ahrens L, Ekblad A, et al. Per- and PolyfluoroalkylContaminated Freshwater Impacts Adjacent Riparian Food Webs. Environ Sci Technol. 2020;54:11951-60.

7. Tsuda S. Differential toxicity between perfluorooctane sulfonate (PFOS) and perfluorooctanoic acid (PFOA). J Toxicol Sci. 2016;41:SP27-SP36.

8. Kang H, Choi K, Lee HS, Kim DH, Park NY, Kim S, et al. Elevated levels of short carbon-chain PFCAs in breast milk among Korean women: Current status and potential challenges. Environ Res. 2016;148:351-9.

9. Nian M, Luo K, Luo F, Aimuzi R, Huo X, Chen Q, et al. Association between Prenatal Exposure to PFAS and Fetal Sex Hormones: Are the Short-Chain PFAS Safer? Environ Sci Technol. 2020:54;8291-9.

10. Tsai MS, Chang SH, Kuo WH, Kuo CH, Li SY, Wang MY, et al. A case-control study of perfluoroalkyl substances and the risk of breast cancer in Taiwanese women. Environ Int. $2020 ; 142,105850$

11. Mancini FR, Cano-Sancho G, Gambaretti J, Marchand P, Boutron-Ruault MC, Severi G, et al. Perfluorinated alkylated substances serum concentration and breast cancer risk: Evidence from a nested case-control study in the French E3N cohort. Int J Cancer. 2020;146:917-28.

12. Beans C. News Feature: How "forever chemicals" might impair the immune system. Proc Natl Acad Sci U S A. 2021;118: 1-5

13. Xu Y, Jurkovic-Mlakar S, Lindh CH, Scott K, Fletcher T, Jakobsson K, et al. Associations between serum concentrations of perfluoroalkyl substances and DNA methylation in women exposed through drinking water: A pilot study in Ronneby, Sweden. Environ Int. 2020;145: 106148 
14. Kim S, Stroski KM, Killeen G, Smitherman C, Simcik MF, Brooks BW. 8:8 Perfluoroalkyl phosphinic acid affects neurobehavioral development, thyroid disruption, and DNA methylation in developing zebrafish. Sci Total Environ. 2020;736:139600

15. DeWitt JC, Blossom SJ, Schaider, L. A. Exposure to per-fluoroalkyl and polyfluoroalkyl substances leads to immunotoxicity: epidemiological and toxicological evidence. J Expo Sci Environ Epidemiol. 2019;29:148-56.

16. Kabir ER, Rahman MS, Rahman I. A review on endocrine disruptors and their possible impacts on human health. Environ Toxicol Pharmacol. 2015;40:241-58.

17. Sonthithai P, Suriyo T, Thiantanawat A, Watcharasit P, Ruchirawat M, Satayavivad J. Perfluorinated chemicals, PFOS and PFOA, enhance the estrogenic effects of 17beta-estradiol in T47D human breast cancer cells. J Appl Toxicol. 2016;36:790-801.

18. Du G, Hu J, Huang H, Qin Y, Han X, Wu D, et al. Perfluorooctane sulfonate (PFOS) affects hormone receptor activity, steroidogenesis, and expression of endocrine-related genes in vitro and in vivo. Environ Toxicol Chem. 2013;32:353-360.

19. Yu WG, Liu W, Jin YH. Effects of perfluorooctane sulfonate on rat thyroid hormone biosynthesis and metabolism. Environ Toxicol Chem. 2009;28:990-6.

20. Mitro SD, Sagiv SK, Fleisch AF, Jaacks LM, Williams PL, Rifas-Shiman SL, et al. Pregnancy Perand Polyfluoroalkyl Substance Concentrations and Postpartum Health in Project Viva: A Prospective Cohort. J Clin Endocrinol Metab. 2020;105: 3415-3426.

21. Gardener H, Sun Q, Grandjean P. PFAS concentration during pregnancy in relation to cardiometabolic health and birth outcomes. Environ Res. 2021;192:110287.

22. Rylander L, Lindh CH, Hansson SR, Broberg K, Kallen K. Per- and Polyfluoroalkyl Substances in Early Pregnancy and Risk for Preeclampsia: A Case-Control Study in Southern Sweden. Toxics. 2020;8: 1-9.

23. Manea S, Salmaso L, Lorenzoni G, Mazzucato M, Russo F, Mantoan D, et al. Exposure to PFAS and small for gestational age new-borns: A birth records study in Veneto Region (Italy). Environ Res. 2020;184:109282

24. Anderko L, Pennea E. Exposures to per-and polyfluoroalkyl substances (PFAS): Potential risks to reproductive and children's health. Curr Probl Pediatr Adolesc Health Care. 2020;50:100760

25. Buck RC, Franklin J, Berger U, Conder JM, Cousins IT, de Voogt P, et al. Perfluoroalkyl and polyfluoroalkyl substances in the environment: terminology, classification, and origins. Integr Environ Assess Manag. 2011;7:513-41.

26. Nickerson A, Rodowa AE, Adamson DT, Field JA, Kulkarni PR, Kornuc JJ, et al. Spatial Trends of Anionic, Zwitterionic, and Cationic PFASs at an AFFF-Impacted Site. Environ Sci Technol. 2021;55:313-23.

27. Brase RA, Mullin EJ, Spink DC. Legacy and Emerging Per- and Polyfluoroalkyl Substances: Analytical Techniques, Environmental Fate, and Health Effects. Int J Mol Sci. 2021;22: 1-30.

28. Barzen-Hanson KA, Roberts SC, Choyke S, Oetjen K, McAlees A, Riddell N, et al. Discovery of 40 Classes of Per- and Polyfluoroalkyl Substances in Historical Aqueous Film-Forming Foams (AFFFs) and AFFF-Impacted Groundwater. Environ Sci Technol. 2017;51:2047-57. 
29. Rayne S, Forest K. Perfluoroalkyl sulfonic and carboxylic acids: a critical review of physicochemical properties, levels and patterns in waters and wastewaters, and treatment methods. J Environ Sci Health A Tox Hazard Subst Environ Eng. 2009;44:1145-99.

30. Cousins IT, DeWitt JC, Gluge J, Goldenman G, Herzke D, Lohmann R, et al. The high persistence of PFAS is sufficient for their management as a chemical class. Environ Sci Process Impacts. 2020;22:2307-12.

31. Higgins, CP, McLeod PB, MacManus-Spencer LA, Luthy RG. Bioaccumulation of perfluorochemicals in sediments by the aquatic oligochaete Lumbriculus variegatus. Environ Sci Technol. 2007;41:4600-6.

32. Kannan K, Tao L, Sinclair E, Pastva SD, Jude DJ, Giesy JP. Perfluorinated compounds in aquatic organisms at various trophic levels in a Great Lakes food chain. Arch Environ Contam Toxicol. 2005;48,559-66.

33. Olsen GW, Church TR, Miller JP, Burris JM, Hansen KJ, Lundberg JK, et al. Perfluorooctanesulfonate and other fluorochemicals in the serum of American Red Cross adult blood donors. Environ Health Perspect. 2003;111:1892-901.

34. Kannan K, Corsolini S, Falandysz J, Fillmann G, Kumar KS, Loganathan BG, et al. Perfluorooctanesulfonate and related fluorochemicals in human blood from several countries. Environ Sci Technol. 2004;38:4489-95.

35. Yamashita N, Kannan K, Taniyasu S, Horii Y, Petrick G, Gamo T. A global survey of perfluorinated acids in oceans. Mar Pollut Bull. 2005;51:658-68.

36. Higgins CP, Field JA, Criddle CS, Luthy RG. Quantitative determination of perfluorochemicals in sediments and domestic sludge. Environ Sci Technol. 2005;39:3946-56.

37. Bossi R, Riget FF, Dietz R, Sonne C, Fauser P, Dam M, et al. Preliminary screening of perfluorooctane sulfonate (PFOS) and other fluorochemicals in fish, birds and marine mammals from Greenland and the Faroe Islands. Environ Pollut. 2005;136:323-39.

38. ITRC. History and Use of Per- and Polyfluoroalkyl Substances (PFAS), 2020.

39. Sunderland EM, Hu XC, Dassuncao C, Tokranov AK, Wagner CC, Allen JG. A review of the pathways of human exposure to poly- and perfluoroalkyl substances (PFASs) and present understanding of health effects. J Expo Sci Environ Epidemiol. 2019;29:131-47.

40. Abunada Z, Alazaiza MYD, Bashir MJK. An Overview of Per- and Polyfluoroalkyl Substances (PFAS) in the Environment: Source, Fate, Risk and Regulations. Water. 2020;12:3590

41. Shi Y, Vestergren R, Xu L, Song X, Niu X, Zhang C, et al. Characterizing direct emissions of perfluoroalkyl substances from ongoing fluoropolymer production sources: A spatial trend study of Xiaoqing River, China. Environmental Pollution. 2015;206:104-12.

42. Bach C, Dauchy X, Boiteux V, Colin A, Hemard J, Sagres V, et al. The impact of two fluoropolymer manufacturing facilities on downstream contamination of a river and drinking water resources with per- and polyfluoroalkyl substances. Environ Sci Pollut Res Int. 2017;24:4916-25.

43. Semerad J, Hatasova N, Grasserova A, Cerna T, Filipova A, Hanc A, et al. Screening for 32 per- and polyfluoroalkyl substances (PFAS) including GenX in sludges from 43 WWTPs located in the Czech Republic - Evaluation of potential accumulation in vegetables after application of biosolids. Chemosphere. 2020;261:128018 
44. Venkatesan AK, Halden RU. National inventory of perfluoroalkyl substances in archived U.S. biosolids from the 2001 EPA National Sewage Sludge Survey. J Hazard Mater. 2013;252-253:413-8.

45. Meegoda JN, Kewalramani JA, Li B, Marsh RW. A Review of the Applications, Environmental Release, and Remediation Technologies of Per- and Polyfluoroalkyl Substances. Int J Environ Res Public Health. 2020;17: 1-26.

46. Stoiber T, Evans S, Naidenko OV. Disposal of products and materials containing per- and polyfluoroalkyl substances (PFAS): A cyclical problem. Chemosphere. 2020;260:127659.

47. Nguyen TMH, Braunig J, Thompson K, Thompson J, Kabiri S, Navarro DA, et al. Influences of Chemical Properties, Soil Properties, and Solution $\mathrm{pH}$ on Soil-Water Partitioning Coefficients of Per- and Polyfluoroalkyl Substances (PFASs). Environ Sci Technol. 2020;54:15883-92.

48. Hoisaeter A, Pfaff A, Breedveld GD. Leaching and transport of PFAS from aqueous film-forming foam (AFFF) in the unsaturated soil at a firefighting training facility under cold climatic conditions. J Contam Hydrol. 2019;222:112-22.

49. Le ST, Kibbey TCG, Weber KP, Glamore WC, O'Carroll DM. A group-contribution model for predicting the physicochemical behavior of PFAS components for understanding environmental fate. Sci Total Environ. 2021;764:142882.

50. Casas G, Martinez-Varela A, Roscales JL, Vila-Costa M, Dachs J, Jimenez B. Enrichment of perfluoroalkyl substances in the sea-surface microlayer and sea-spray aerosols in the Southern Ocean. Environ Pollut. 2020;267:115512.

51. Mussabek D, Ahrens L, Persson KM, Berndtsson R. Temporal trends and sediment-water partitioning of per- and polyfluoroalkyl substances (PFAS) in lake sediment. Chemosphere. 2019;227:624-9.

52. Liu Y, Zhang Y, Li J, Wu N, Li W, Niu Z. Distribution, partitioning behavior and positive matrix factorization-based source analysis of legacy and emerging polyfluorinated alkyl substances in the dissolved phase, surface sediment and suspended particulate matter around coastal areas of Bohai Bay, China. Environ Pollut. 2019;246:34-44.

53. Dimzon IK, Westerveld J, Gremmel C, Fromel T, Knepper TP, de Voogt P. Sampling and simultaneous determination of volatile per- and polyfluoroalkyl substances in wastewater treatment plant air and water. Anal Bioanal Chem. 2017;409:1395-404.

54. Schroeder T, Bond D, Foley J. PFAS soil and groundwater contamination via industrial airborne emission and land deposition in SW Vermont and Eastern New York State, USA. Environ Sci Process Impacts. 2021;23:291-301.

55. Sharifan H, Bagheri M, Wang D, Burken JG, Higgins CP, Liang Y, et al. Fate and transport of perand polyfluoroalkyl substances (PFASs) in the vadose zone. Sci Total Environ. 2021;771:145427.

56. Shin HM, Vieira VM, Ryan PB, Detwiler R, Sanders B, Steenland K, et al. Environmental fate and transport modeling for perfluorooctanoic acid emitted from the Washington Works Facility in West Virginia. Environ Sci Technol. 2011;45:1435-42.

57. Hunter Anderson R, Adamson DT, Stroo HF. Partitioning of poly- and perfluoroalkyl substances from soil to groundwater within aqueous film-forming foam source zones. J Contam Hydrol. 2019;220:59-65. 
58. Skaar JS, Raeder EM, Lyche JL, Ahrens L, Kallenborn R. Elucidation of contamination sources for poly- and perfluoroalkyl substances (PFASs) on Svalbard (Norwegian Arctic). Environ Sci Pollut Res Int. 2019;26:7356-63.

59. Knutsen H, Maehlum T, Haarstad K, Slinde GA, Arp HPH. Leachate emissions of short- and longchain per- and polyfluoralkyl substances (PFASs) from various Norwegian landfills. Environ Sci Process Impacts. 2019;21:1970-9.

60. Lenka, SP, Kah M, Padhye LP. A review of the occurrence, transformation, and removal of polyand perfluoroalkyl substances (PFAS) in wastewater treatment plants. Water Res. 2021;199:117187.

61. Li R, Munoz G, Liu Y, Sauve S, Ghoshal S, Liu J. Transformation of novel polyfluoroalkyl substances (PFASs) as co-contaminants during biopile remediation of petroleum hydrocarbons. J Hazard Mater. 2019;362:140-7.

62. Ellis DA, Martin JW, De Silva AO, Mabury SA, Hurley MD, Sulbaek Andersen MP, et al. Degradation of fluorotelomer alcohols: a likely atmospheric source of perfluorinated carboxylic acids. Environ Sci Technol. 2004;38:3316-21.

63. Zhang H, Wang SL, Yu Y. [Concentrations of Typical Perfluoroalkyl Acids and Contributions of Their Precursors in the Water of the Le'an River in China]. Huan Jing Ke Xue. 2020;41,3204-11.

64. Butt CM, Muir DC, Mabury SA. Biotransformation pathways of fluorotelomer-based polyfluoroalkyl substances: a review. Environ Toxicol Chem. 2014;33:243-67.

65. Langberg HA, Breedveld GD, Slinde GA, Gronning HM, Hoisaeter A, Jartun M, et al. Fluorinated Precursor Compounds in Sediments as a Source of Perfluorinated Alkyl Acids (PFAA) to Biota. Environ Sci Technol. 2020;54:13077-89.

66. 3M [Internet]. Phase-out plan for PSOF based compounds, 2020.Available from: https://archive.epa.gov/epapages/newsroom_archive/newsreleases/33aa946e6cb11f35852568e1005 246b4.html.

67. US-EPA [Internet]. Fact Sheet: 2010/2015 PFOA Stewardship Program, 2020.Avaliable from: https://www.epa.gov/assessing-and-managing-chemicals-under-tsca/fact-sheet-20102015-pfoastewardship-program.

68. EP-CEU [Internet]. REGULATION (EU) 2019/1021 OF THE EUROPEAN PARLIAMENT AND OF THE COUNCIL of 20 June 2019 on persistent organic pollutants. Official Journal of the European Union, 2019. Available from: https:/eur-lex.europa.eu/eli/reg/2019/1021/oj.

69. EP-CEU [Internet]. Amending Annex I to Regulation (EU) 2019/1021 of the European Parliament and of the Council as regards the entry for perfluorooctane sulfonic acid and its derivatives (PFOS). Official Journal of the European Union, 2020. Available from: https://eurlex.europa.eu/eli/reg_del/2020/1203/oj.

70. Chemicalwatch [Internet]. Global ban on PFOA enters into force for most countries, 2020. Available from: https://chemicalwatch.com/189390/global-ban-on-pfoa-enters-into-force-for-most-countries

71. EP-CEU [Internet]. Amending Annex I to Regulation (EU) 2019/1021 of the European Parliament and of the Council as regards the listing of perfluorooctanoic acid (PFOA), its salts and PFOA-related compounds. Official Journal of the European Union, 2020. Available from: https:/eurlex.europa.eu/legal-content/EN/TXT/?uri=pi_com\%3AAres\%282019\%296890180. 
72. Poothong S, Papadopoulou E, Padilla-Sanchez JA, Thomsen C, Haug LS. Multiple pathways of human exposure to poly- and perfluoroalkyl substances (PFASs): From external exposure to human blood. Environ Int. 2020;134:105244.

73. Arinaitwe K, Keltsch N, Taabu-Munyaho A, Reemtsma T, Berger U. Perfluoroalkyl substances (PFASs) in the Ugandan waters of Lake Victoria: Spatial distribution, catchment release and public exposure risk via municipal water consumption. Sci Total Environ. 2021;783:146970.

74. Hansen S, Vestergren R, Herzke D, Melhus M, Evenset A, Hanssen L, et al. Exposure to per- and polyfluoroalkyl substances through the consumption of fish from lakes affected by aqueous filmforming foam emissions - A combined epidemiological and exposure modeling approach. The SAMINOR 2 Clinical Study. Environ Int. 2016;94:272-82.

75. Li N, Ying GG, Hong H, Deng WJ. Perfluoroalkyl substances in the urine and hair of preschool children, airborne particles in kindergartens, and drinking water in Hong Kong. Environ Pollut. 2021;270:116219.

76. Xu Y, Fletcher T, Pineda D, Lindh CH, Nilsson C, Glynn A, et al. Serum Half-Lives for Short- and Long-Chain Perfluoroalkyl Acids after Ceasing Exposure from Drinking Water Contaminated by Firefighting Foam. Environ Health Perspect. 2020;128:77004.

77. Forsthuber M, Kaiser AM, Granitzer S, Hassl I, Hengstschlager M, Stangl H, et al. Albumin is the major carrier protein for PFOS, PFOA, PFHxS, PFNA and PFDA in human plasma. Environ Int. 2020;137:105324.

78. Kar S, Sepulveda MS, Roy K, Leszczynski J. Endocrine-disrupting activity of per- and polyfluoroalkyl substances: Exploring combined approaches of ligand and structure based modeling. Chemosphere. 2017;184:514-23.

79. Blake BE, Fenton SE. Early life exposure to per- and polyfluoroalkyl substances (PFAS) and latent health outcomes: A review including the placenta as a target tissue and possible driver of peri- and postnatal effects. Toxicology. 2020;443:152565.

80. Khazaee M, Christie E, Cheng W, Michalsen M, Field J, Ng C. Perfluoroalkyl Acid Binding with Peroxisome Proliferator-Activated Receptors alpha, gamma, and delta, and Fatty Acid Binding Proteins by Equilibrium Dialysis with a Comparison of Methods. Toxics. 2021;9: 1-15.

81. Lai TT, Eken Y, Wilson AK. Binding of Per- and Polyfluoroalkyl Substances to the Human Pregnane X Receptor. Environ Sci Technol. 2020;54:15986-95.

82. Zoeller RT, Brown TR, Doan LL, Gore AC, Skakkebaek NE, Soto AM, et al. Endocrine-disrupting chemicals and public health protection: a statement of principles from The Endocrine Society. Endocrinology. 2012;153:4097-110.

83. Serra H, Beausoleil C, Habert R, Minier C, Picard-Hagen N, Michel C. Evidence for Bisphenol B Endocrine Properties: Scientific and Regulatory Perspectives. Environ Health Perspect. 2019;127:106001.

84. Boas M, Feldt-Rasmussen U, Main KM. Thyroid effects of endocrine disrupting chemicals. Mol Cell Endocrinol. 2012;355:240-8.

85. Nowak K, Jablonska E, Ratajczak-Wrona W. Immunomodulatory effects of synthetic endocrine disrupting chemicals on the development and functions of human immune cells. Environ Int. 2019;125:350-64. 
86. Soundararajan A, Prabu P, Mohan V, Gibert Y, Balasubramanyam M. Novel insights of elevated systemic levels of bisphenol-A (BPA) linked to poor glycemic control, accelerated cellular senescence and insulin resistance in patients with type 2 diabetes. Mol Cell Biochem. 2019;458:171-83.

87. Sifakis S, Androutsopoulos VP, Tsatsakis AM, Spandidos DA. Human exposure to endocrine disrupting chemicals: effects on the male and female reproductive systems. Environ Toxicol Pharmacol. 2017;51:56-70.

88. Olaniyan LWB, Okoh AI. Determination and ecological risk assessment of two endocrine disruptors from River Buffalo, South Africa. Environ Monit Assess. 2020;192:750.

89. Filipkowska A, Lubecki L. Endocrine disruptors in blue mussels and sediments from the Gulf of Gdansk (Southern Baltic). Environ Sci Pollut Res Int. 2016;23:13864-13876.

90. Fellowes R, Fortune F, Bergmeier LA, Lehner T. The effect of immunization with a 14-kDa streptococcal antigen on primate T cell and B cell responses. Eur J Immunol. 1988;18:559-64.

91. FitzGerald RE. Perspective on Health Effects of Endocrine Disruptors with a Focus on Data Gaps. Chem Res Toxicol. 2020;33:1284-91.

92. Yilmaz B, Terekeci H, Sandal S, Kelestimur F. Endocrine disrupting chemicals: exposure, effects on human health, mechanism of action, models for testing and strategies for prevention. Rev Endocr Metab Disord. 2020;21:127-47.

93. Cardenas A, Hauser R, Gold DR, Kleinman KP, Hivert MF, Fleisch AF, et al. Association of Perfluoroalkyl and Polyfluoroalkyl Substances With Adiposity. JAMA Netw Open. 2018;1:e181493.

94. Rodriguez-Jorquera IA, Colli-Dula RC, Kroll K, Jayasinghe BS, Parachu Marco MV, Silva-Sanchez C, et al. Blood Transcriptomics Analysis of Fish Exposed to Perfluoro Alkyls Substances: Assessment of a Non-Lethal Sampling Technique for Advancing Aquatic Toxicology Research. Environ Sci Technol. 2019;53:1441-52.

95. Kovarich S, Papa E, Li J, Gramatica P. QSAR classification models for the screening of the endocrine-disrupting activity of perfluorinated compounds. SAR QSAR Environ Res. 2012;23:207-20.

96. Ren XM, Zhang YF, Guo LH, Qin ZF, Lv QY, Zhang LY. Structure-activity relations in binding of perfluoroalkyl compounds to human thyroid hormone T3 receptor. Arch Toxicol. 2015;89:233-42.

97. Pelch KE, Reade A, Wolffe TAM, Kwiatkowski CF. PFAS health effects database: Protocol for a systematic evidence map. Environ Int. 2019;130:104851.

98. TEDX. (2021) The Endocrine Disruption Exchange [Internet]. Available from: https://endocrinedisruption.org.

99. Chen L, Hu C, Tsui MMP, Wan T, Peterson DR, Shi Q, et al. Multigenerational Disruption of the Thyroid Endocrine System in Marine Medaka after a Life-Cycle Exposure to Perfluorobutanesulfonate. Environ Sci Technol. 2018;52:4432-9.

100. Kim DH, Kim UJ, Kim HY, Choi SD, Oh JE. Perfluoroalkyl substances in serum from South Korean infants with congenital hypothyroidism and healthy infants--Its relationship with thyroid hormones. Environ Res. 2016;147:399-404.

101. Nian M, Li QQ, Bloom M, Qian ZM, Syberg KM, Vaughn MG, et al. Liver function biomarkers disorder is associated with exposure to perfluoroalkyl acids in adults: Isomers of C8 Health Project in China. Environ Res. 2019;172:81-8. 
102. Conley JM, Lambright CS, Evans N, Strynar MJ, McCord J, McIntyre BS, et al. Adverse Maternal, Fetal, and Postnatal Effects of Hexafluoropropylene Oxide Dimer Acid (GenX) from Oral Gestational Exposure in Sprague-Dawley Rats. Environ Health Perspect. 2019;127:37008.

103. Ernst A, Brix N, Lauridsen LLB, Olsen J, Parner ET, Liew Z, et al. Exposure to Perfluoroalkyl Substances during Fetal Life and Pubertal Development in Boys and Girls from the Danish National Birth Cohort. Environ Health Perspect. 2019;127:17004.

104. Di Nisio A, De Rocco Ponce M, Giadone A, Rocca MS, Guidolin D, Foresta C. Perfluoroalkyl substances and bone health in young men: a pilot study. Endocrine. 2020;67:678-84.

105. Li N, Liu Y, Papandonatos GD, Calafat AM, Eaton CB, Kelsey KT, et al. Gestational and childhood exposure to per- and polyfluoroalkyl substances and cardiometabolic risk at age 12 years. Environ Int. 2021;147:106344.

106. Houck KA, Patlewicz G, Richard AM, Williams AJ, Shobair MA, Smeltz M, et al. Bioactivity profiling of per- and polyfluoroalkyl substances (PFAS) identifies potential toxicity pathways related to molecular structure. Toxicology. 2021;457:152789.

107. Weiss JM, Andersson PL, Lamoree MH, Leonards PE, van Leeuwen SP, Hamers T. Competitive binding of poly- and perfluorinated compounds to the thyroid hormone transport protein transthyretin. Toxicol Sci. 2009;109:206-16.

108. Wen LL, Lin CY, Chou HC, Chang CC, Lo HY, Juan SH. Perfluorooctanesulfonate Mediates Renal Tubular Cell Apoptosis through PPARgamma Inactivation. PLoS One. 2016;11:e0155190.

109. Almeida NMS, Eken Y, Wilson AK. Binding of Per- and Polyfluoro-alkyl Substances to Peroxisome Proliferator-Activated Receptor Gamma. ACS Omega. 2021;6:15103-14.

110. Kjeldsen LS, Bonefeld-Jorgensen EC. Perfluorinated compounds affect the function of sex hormone receptors. Environ Sci Pollut Res Int. 2013;20:8031-44.

111. Zhang YM, Dong XY, Fan LJ, Zhang ZL, Wang Q, Jiang N, et al. Poly- and perfluorinated compounds activate human pregnane X receptor. Toxicology. 2017;380:23-9.

112. Di Nisio A, Rocca MS, De Toni L, Sabovic I, Guidolin D, Dall'Acqua S, et al. Endocrine disruption of vitamin D activity by perfluoro-octanoic acid (PFOA). Sci Rep. 2020;10:16789.

113. Ren XM, Qin WP, Cao LY, Zhang J, Yang Y, Wan B, et al. Binding interactions of perfluoroalkyl substances with thyroid hormone transport proteins and potential toxicological implications. Toxicology. 2016;366-367:32-42.

114. Bach CC, Vested A, Jorgensen KT, Bonde JP, Henriksen TB, Toft G. Perfluoroalkyl and polyfluoroalkyl substances and measures of human fertility: a systematic review. Crit Rev Toxicol. 2016;46:735-55.

115. Di Nisio A, Sabovic I, Valente U, Tescari S, Rocca MS, Guidolin D, et al. Endocrine Disruption of Androgenic Activity by Perfluoroalkyl Substances: Clinical and Experimental Evidence. J Clin Endocrinol Metab. 2019;104:1259-71.

116. Shi Z, Ding L, Zhang H, Feng Y, Xu M, Dai J. Chronic exposure to perfluorododecanoic acid disrupts testicular steroidogenesis and the expression of related genes in male rats. Toxicol Lett. 2009; 188:192-200.

117. Lopez-Doval S, Salgado R, Pereiro N, Moyano R, Lafuente A. Perfluorooctane sulfonate effects on the reproductive axis in adult male rats. Environ Res. 2014;134:158-68. 
118. Lopez-Doval S, Salgado R, Lafuente A. The expression of several reproductive hormone receptors can be modified by perfluorooctane sulfonate (PFOS) in adult male rats. Chemosphere. 2016;155:488-97.

119. Kang JS, Choi JS, Park JW. Transcriptional changes in steroidogenesis by perfluoroalkyl acids (PFOA and PFOS) regulate the synthesis of sex hormones in H295R cells. Chemosphere. 2016;155:436-43.

120. Chaparro-Ortega A, Betancourt M, Rosas P, Vazquez-Cuevas FG, Chavira R, Bonilla E, et al. Endocrine disruptor effect of perfluorooctane sulfonic acid (PFOS) and perfluorooctanoic acid (PFOA) on porcine ovarian cell steroidogenesis. Toxicol In Vitro. 2018;46:86-93.

121. Toft G, Jonsson BA, Lindh CH, Giwercman A, Spano M, Heederik D, et al. Exposure to perfluorinated compounds and human semen quality in Arctic and European populations. Hum Reprod. 2012;27:2532-40.

122. Louis GM, Chen Z, Schisterman EF, Kim S, Sweeney AM, Sundaram R, et al. Perfluorochemicals and human semen quality: the LIFE study. Environ Health Perspect. 2015;123:57-63.

123. Barrett ES, Chen C, Thurston SW, Haug LS, Sabaredzovic A, Fjeldheim FN, et al. Perfluoroalkyl substances and ovarian hormone concentrations in naturally cycling women. Fertil Steril. 2015;103:1261-70.

124. Tsai MS, Lin CY, Lin CC, Chen MH, Hsu SH, Chien KL, et al. Association between perfluoroalkyl substances and reproductive hormones in adolescents and young adults. Int J Hyg Environ Health. 2015;218:437-43.

125. Velez MP, Arbuckle TE, Fraser WD. Maternal exposure to perfluorinated chemicals and reduced fecundity: the MIREC study. Hum Reprod. 2015;30:701-9.

126. Fei C, McLaughlin JK, Lipworth L, Olsen J. Maternal levels of perfluorinated chemicals and subfecundity. Hum Reprod. 2009;24:1200-5.

127. Ding J, Zhou H, Liu Y, Cai J, Longnecker MP. Estimating effect of environmental contaminants on women's subfecundity for the MoBa study data with an outcome-dependent sampling scheme. Biostatistics. 2014;15:636-50.

128. Jin ML. [Combined UFTM for 140 patients with advanced gastric cancer]. Zhonghua Zhong Liu Za Zhi. 1989;11:130-2.

129. Wikstrom S, Hussein G, Lingroth Karlsson A, Lindh CH, Bornehag CG. Exposure to perfluoroalkyl substances in early pregnancy and risk of sporadic first trimester miscarriage. Sci Rep. 2021;11:3568.

130. Wang B, Zhang R, Jin F, Lou H, Mao Y, Zhu W, et al. Perfluoroalkyl substances and endometriosisrelated infertility in Chinese women. Environ Int. 2017;102:207-12.

131. Zhang S, Tan R, Pan R, Xiong J, Tian Y, Wu J, et al. Association of Perfluoroalkyl and Polyfluoroalkyl Substances With Premature Ovarian Insufficiency in Chinese Women. J Clin Endocrinol Metab. 2018;103:2543-51.

132. Di Nisio A, Rocca MS, Sabovic I, De Rocco Ponce M, Corsini C, Guidolin D, et al. Perfluorooctanoic acid alters progesterone activity in human endometrial cells and induces reproductive alterations in young women. Chemosphere. 2020;242:125208.

133. Erinc A, Davis MB, Padmanabhan V, Langen E, Goodrich JM. Considering environmental exposures to per- and polyfluoroalkyl substances (PFAS) as risk factors for hypertensive disorders of pregnancy. Environ Res. 2021;197:111113. 
134. Yahia D, El-Nasser MA, Abedel-Latif M, Tsukuba C, Yoshida M, Sato I, et al. Effects of perfluorooctanoic acid (PFOA) exposure to pregnant mice on reproduction. J Toxicol Sci. 2010;35:527-33.

135. Song $\mathrm{P}$, Li D, Wang X, Zhong X. Effects of perfluorooctanoic acid exposure during pregnancy on the reproduction and development of male offspring mice. Andrologia. 2018;50:e13059.

136. Das KP, Grey BE, Rosen MB, Wood CR, Tatum-Gibbs KR, Zehr RD, et al. Developmental toxicity of perfluorononanoic acid in mice. Reprod Toxicol. 2015;51:133-44.

137. Kashino I, Sasaki S, Okada E, Matsuura H, Goudarzi H, Miyashita C, et al. Prenatal exposure to 11 perfluoroalkyl substances and fetal growth: A large-scale, prospective birth cohort study. Environ Int. 2020;136:105355.

138. Li M, Zeng XW, Qian ZM, Vaughn MG, Sauve S, Paul G, et al. Isomers of perfluorooctanesulfonate (PFOS) in cord serum and birth outcomes in China: Guangzhou Birth Cohort Study. Environ Int. 2017; 102:1-8.

139. Wang H, Du H, Yang J, Jiang H, O K, Xu L, et al. PFOS, PFOA, estrogen homeostasis, and birth size in Chinese infants. Chemosphere. 2019;221:349-55.

140. Yao Q, Gao Y, Zhang Y, Qin K, Liew Z, Tian Y. Associations of paternal and maternal per- and polyfluoroalkyl substances exposure with cord serum reproductive hormones, placental steroidogenic enzyme and birth weight. Chemosphere. 2021;285:131521.

141. Pearce JL, Neelon B, Bloom MS, Buckley JP, Ananth CV, Perera F, et al. Exploring associations between prenatal exposure to multiple endocrine disruptors and birth weight with exposure continuum mapping. Environ Res. 2021;200:111386.

142. Gundacker C, Graf-Rohrmeister K, Gencik M, Hengstschlager M, Holoman K, Rosa P, et al. Gene Variants Determine Placental Transfer of Perfluoroalkyl Substances (PFAS), Mercury (Hg) and Lead $(\mathrm{Pb})$, and Birth Outcome: Findings From the UmMuKi Bratislava-Vienna Study. Front Genet. 2021;12:664946.

143. Kung YP, Lin CC, Chen MH, Tsai MS, Hsieh WS, Chen PC. Intrauterine exposure to per- and polyfluoroalkyl substances may harm children's lung function development. Environ Res. 2021;192:110178.

144. Chen MH, Ha EH, Liao HF, Jeng SF, Su YN, Wen TW, et al. Perfluorinated compound levels in cord blood and neurodevelopment at 2 years of age. Epidemiology. 2013;24:800-8.

145. Wang Y, Rogan WJ, Chen HY, Chen PC, Su PH, Chen HY, et al. Prenatal exposure to perfluroalkyl substances and children's IQ: The Taiwan maternal and infant cohort study. Int J Hyg Environ Health. 2015;218:639-44.

146. Vuong AM, Yolton K, Webster GM, Sjodin A, Calafat AM, Braun JM, et al. Prenatal polybrominated diphenyl ether and perfluoroalkyl substance exposures and executive function in school-age children. Environ Res. 2016;147:556-64.

147. Oulhote Y, Steuerwald U, Debes F, Weihe P, Grandjean P. Behavioral difficulties in 7-year old children in relation to developmental exposure to perfluorinated alkyl substances. Environ Int. 2016;97:237-45.

148. Niu J, Liang H, Tian Y, Yuan W, Xiao H, Hu H, et al. Prenatal plasma concentrations of Perfluoroalkyl and polyfluoroalkyl substances and neuropsychological development in children at four years of age. Environ Health. 2019;18:53. 
149. Oh J, Bennett DH, Calafat AM, Tancredi D, Roa DL, Schmidt RJ, et al. Prenatal exposure to perand polyfluoroalkyl substances in association with autism spectrum disorder in the MARBLES study. Environ Int. 2021;147:106328.

150. Hines EP, White SS, Stanko JP, Gibbs-Flournoy EA, Lau C, Fenton SE. Phenotypic dichotomy following developmental exposure to perfluorooctanoic acid (PFOA) in female CD-1 mice: Low doses induce elevated serum leptin and insulin, and overweight in mid-life. Mol Cell Endocrinol. 2009;304:97-105.

151. Lv Z, Li G, Li Y, Ying C, Chen J, Chen T, et al. Glucose and lipid homeostasis in adult rat is impaired by early-life exposure to perfluorooctane sulfonate. Environ Toxicol. 2013;28:532-42.

152. Wang L, Wang Y, Liang Y, Li J, Liu Y, Zhang J, et al. PFOS induced lipid metabolism disturbances in BALB/c mice through inhibition of low density lipoproteins excretion. Sci Rep. 2014;4:4582.

153. Lu Y, Pan Y, Sheng N, Zhao AZ, Dai J. Perfluorooctanoic acid exposure alters polyunsaturated fatty acid composition, induces oxidative stress and activates the AKT/AMPK pathway in mouse epididymis. Chemosphere. 2016;158:143-53.

154. Watkins AM, Wood CR, Lin MT, Abbott BD. The effects of perfluorinated chemicals on adipocyte differentiation in vitro. Mol Cell Endocrinol. 2015;400:90-101.

155. Xu J, Shimpi P, Armstrong L, Salter D, Slitt AL. PFOS induces adipogenesis and glucose uptake in association with activation of Nrf2 signaling pathway. Toxicol Appl Pharmacol. 2016;290:21-30.

156. Andersen CS, Fei C, Gamborg M, Nohr EA, Sorensen TI, Olsen J. Prenatal exposures to perfluorinated chemicals and anthropometry at 7 years of age. Am J Epidemiol. 2013;178:921-7.

157. Martinsson M, Nielsen C, Bjork J, Rylander L, Malmqvist E, Lindh C, et al. Intrauterine exposure to perfluorinated compounds and overweight at age 4: A case-control study. PLoS One. 2020;15:e0230137.

158. Lauritzen HB, Larose TL, Oien T, Sandanger TM, Odland JO, van de Bor M, et al. Prenatal exposure to persistent organic pollutants and child overweight/obesity at 5-year follow-up: a prospective cohort study. Environ Health. 2018;17:9.

159. Hartman TJ, Calafat AM, Holmes AK, Marcus M, Northstone K, Flanders WD, et al. Prenatal Exposure to Perfluoroalkyl Substances and Body Fatness in Girls. Child Obes. 2017;13:222-30.

160. Jansen A, Muller MHB, Gronnestad R, Klungsoyr O, Polder A, Skjerve E, et al. Decreased plasma levels of perfluoroalkylated substances one year after bariatric surgery. Sci Total Environ. 2019;657:863-70.

161. Halldorsson TI, Rytter D, Haug LS, Bech BH, Danielsen I, Becher G, et al. Prenatal exposure to perfluorooctanoate and risk of overweight at 20 years of age: a prospective cohort study. Environ Health Perspect. 2012;120:668-73.

162. Braun JM, Chen A, Romano ME, Calafat AM, Webster GM, Yolton K, et al. Prenatal perfluoroalkyl substance exposure and child adiposity at 8 years of age: The HOME study. Obesity (Silver Spring). 2016;24:231-7.

163. Mora AM, Oken E, Rifas-Shiman SL, Webster TF, Gillman MW, Calafat AM, et al. Prenatal Exposure to Perfluoroalkyl Substances and Adiposity in Early and Mid-Childhood. Environ Health Perspect. 2017;125:467-73. 
164. Karlsen M, Grandjean P, Weihe P, Steuerwald U, Oulhote Y, Valvi D. Early-life exposures to persistent organic pollutants in relation to overweight in preschool children. Reprod Toxicol. 2017;68:145-53.

165. Tian YP, Zeng XW, Bloom MS, Lin S, Wang SQ, Yim SHL, et al. Isomers of perfluoroalkyl substances and overweight status among Chinese by sex status: Isomers of C8 Health Project in China. Environ Int. 2019;124:130-8.

166. Geiger SD, Yao P, Vaughn MG, Qian Z. PFAS exposure and overweight/obesity among children in a nationally representative sample. Chemosphere. 2021;268:128852.

167. Averina M, Brox J, Huber S, Furberg AS. Exposure to perfluoroalkyl substances (PFAS) and dyslipidemia, hypertension and obesity in adolescents. The Fit Futures study. Environ Res. 2021;195:110740.

168. Coperchini F, Croce L, Ricci G, Magri F, Rotondi M, Imbriani M, et al. () Thyroid Disrupting Effects of Old and New Generation PFAS. Front Endocrinol (Lausanne). 2020;11:612320.

169. Brent GA. Mechanisms of thyroid hormone action. J Clin Invest. 2012;122:3035-43.

170. Wang J, Hallinger DR, Murr AS, Buckalew AR, Lougee RR, Richard AM, et al. High-throughput screening and chemotype-enrichment analysis of ToxCast phase II chemicals evaluated for human sodium-iodide symporter (NIS) inhibition. Environ Int. 2019;126:377-86.

171. Conti A, Strazzeri C, Rhoden KJ. Perfluorooctane sulfonic acid, a persistent organic pollutant, inhibits iodide accumulation by thyroid follicular cells in vitro. Mol Cell Endocrinol. 2020;515:110922.

172. Song M, Kim YJ, Park YK, Ryu JC. Changes in thyroid peroxidase activity in response to various chemicals. J Environ Monit. 2012;14:2121-6.

173. Itoh S, Araki A, Miyashita C, Yamazaki K, Goudarzi H, Minatoya M, et al. Association between perfluoroalkyl substance exposure and thyroid hormone/thyroid antibody levels in maternal and cord blood: The Hokkaido Study. Environ Int. 2019;133:105139.

174. Webster GM, Venners SA, Mattman A, Martin JW. Associations between perfluoroalkyl acids (PFASs) and maternal thyroid hormones in early pregnancy: a population-based cohort study. Environ Res. 2014;133:338-47.

175. Guo J, Zhang J, Wang Z, Zhang L, Qi X, Zhang Y, et al. Umbilical cord serum perfluoroalkyl substance mixtures in relation to thyroid function of newborns: Findings from Sheyang Mini Birth Cohort Study. Chemosphere. 2021;273:129664.

176. Preston EV, Webster TF, Oken E, Claus Henn B, McClean MD, Rifas-Shiman SL, et al. Maternal Plasma per- and Polyfluoroalkyl Substance Concentrations in Early Pregnancy and Maternal and Neonatal Thyroid Function in a Prospective Birth Cohort: Project Viva (USA). Environ Health Perspect. 2018;126:027013.

177. Preston EV, Webster TF, Claus Henn B, McClean MD, Gennings C, Oken E, et al. Prenatal exposure to per- and polyfluoroalkyl substances and maternal and neonatal thyroid function in the Project Viva Cohort: A mixtures approach. Environ Int. 2020;139:105728.

178. Caron-Beaudoin E, Ayotte P, Laouan Sidi EA, et al. Exposure to perfluoroalkyl substances (PFAS) and associations with thyroid parameters in First Nation children and youth from Quebec. Environ Int. 2019;128:13-23. 
179. Lopez-Espinosa MJ, Mondal D, Armstrong B, Bloom MS, Fletcher T. Thyroid function and perfluoroalkyl acids in children living near a chemical plant. Environ Health Perspect. 2012;120:1036-41.

180. Lin CY, Wen LL, Lin LY, Wen TW, Lien GW, Hsu SH, et al. The associations between serum perfluorinated chemicals and thyroid function in adolescents and young adults. J Hazard Mater. 2013;244-245:637-44.

181. Blake BE, Pinney SM, Hines EP, Fenton SE, Ferguson KK. Associations between longitudinal serum perfluoroalkyl substance (PFAS) levels and measures of thyroid hormone, kidney function, and body mass index in the Fernald Community Cohort. Environ Pollut. 2018;242:894-904. 


\title{
PFAS supstance kao endokrini ometači: ozbiljna bojazan povezana sa tradicionalnim i zamenskim supstancama
}

\author{
Emiliano Panieri $^{{ }^{*}}$, Aleksandra Buha Đorđevic ${ }^{2}$, Luciano Saso ${ }^{1}$ \\ ${ }^{1}$ Department of Physiology and Pharmacology "Vittorio Erspamer”, Sapienza \\ University of Rome, 00185 Rome, Italy \\ ${ }^{2}$ Univerzitet u Beogradu - Farmaceutski fakultet, Katedra za toksikologiju „Akademik \\ Danilo Soldatović“, Beograd, Srbija
}

* Autor za korespondenciju: Emiliano Panieri, e-mail: emiliano.panieri@isprambiente.it

\section{Kratak sadržaj}

Zahvaljujući svojim izuzetnim svojstvima, raznovrsnoj primeni i hemijskoj stabilnosti, peri poli-fluoralkil supstance (PFAS) se decenijama koriste u najrazličitijim procesima i proizvodima. Međutim, sve se više govori o tome da ove supstance mogu predstavljati ozbiljnu pretnju po zdravlje ljudi i živih organizama usled svoje postojanosti, sposobnosti prenošenja na velikim udaljenostima i tendencije da se akumuliraju u živim organizmima. Iz ovog razloga, širom EU činjeni su određeni napori da se identifikuju alternativni molekuli, kraćeg ugljeničnog lanca i teoretski bezbednijeg profila, koji bi mogli da zamene prethodnu generaciju tradicionalnih PFAS supstanci. Nažalost, ova strategija nije bila u potpunosti uspešna, te PFAS supstance i dalje predstavljaju ozbiljan razlog za zabrinutost. Između ostalog, jedan od aspekata koji dobija na značaju su i štetni efekti koje i tradicionalne i alternativne PFAS supstance mogu imati na endokrini sistem, naročito kod osetljivih podgrupa stanovništva. U ovom preglednom radu je dat kratak rezime svojstava PFAS supstanci, njihove upotrebe i sudbine u životnoj sredini, sa fokusom na njihovo dejstvo na reproduktivnu sposobnost i plodnost ljudi, metabolizam i gojaznost, kao i na tiroidnu funkciju.

Ključne reči: PFAS; zdravlje ljudi; ometanje endokrine funkcije; životna sredina 